
\title{
$\begin{array}{ll}\text { Research Square } & \begin{array}{l}\text { Preprints are preliminary reports that have not undergone peer review. } \\ \text { They should not be considered conclusive, used to inform clinical practice, } \\ \text { or referenced by the media as validated information. }\end{array}\end{array}$
}

\section{Assessment of Musculoskeletal Pain, Fatigue and Grip Strength in Hospitalized Patients with COVID-19}

Sansin Tuzun ( $\nabla$ sansin@istanbul.edu.tr)

Istanbul University-Cerrahpasa, Cerrahpasa Medical Faculty https://orcid.org/0000-0002-3300-2286

Aslinur Keles

Istanbul University-Cerrahpasa, Cerrahpasa Medical Faculty https://orcid.org/0000-0003-0651-0557

dilara okutan

Istanbul University-Cerrahpasa, Cerrahpasa Medical Faculty https://orcid.org/0000-0001-5723-8704

Tugbay Yildiran

Istanbul University-Cerrahpasa, Cerrahpasa Medical Faculty https://orcid.org/0000-0003-4035-237X

Deniz Palamar

Istanbul University-Cerrahpasa, Cerrahpasa Medical Faculty https://orcid.org/0000-0003-2882-2578

\section{Research Article}

Keywords: COVID-19, myalgia, fatigue, arthralgia, back pain, grip strength

Posted Date: August 12th, 2020

DOI: https://doi.org/10.21203/rs.3.rs-56548/v1

License: (c) (7) This work is licensed under a Creative Commons Attribution 4.0 International License. Read Full License 


\section{Abstract}

IMPORTANCE Coronavirus disease 2019 (COVID-19) is an emerging disease that was declared as a pandemic by WHO. Although there are many retrospective studies to present clinical aspects of the COVID-19, still the involvement of the musculoskeletal system has not been deeply investigated.

OBJECTIVE To classify the symptoms of musculoskeletal system in COVID-19 patients, to evaluate myalgia, arthralgia and physical/mental fatigue, to assess handgrip muscle strength, and to examine the relationship of these parameters with the severity and laboratory values of the disease.

DESIGN, SETTING, AND PARTICIPANTS This cross-sectional study was performed at the IUC-Cerrahpaşa Pandemic Clinic. Hospitalized 150 adults with laboratory and radiological confirmation of severe acute respiratory syndrome coronavirus 2 (SARS-CoV-2) according to WHO interim guidance were included in the study. Data were recorded from May 15,2020, to June 30, 2020.

MAIN OUTCOMES AND MEASURES Demographic data, comorbidities, musculoskeletal symptoms, laboratory findings and CT scans were recorded. To determine the disease severity 2007 idsa/ats guidelines for community acquired pneumonia was used. Myalgia severity was calculated by numerical rating scale (NRS). Visual analog scale and Chalder Fatigue Scale (CFS) were used for fatigue severity determination. Handgrip strength (HGS) was measured by Jamar hand dynamometer.

RESULTS 103 patients (68.7\%) were nonsevere and 47 patients (31.3\%) were severe. The most common musculoskeletal symptom was fatigue (133 [85.3\%]), followed by myalgia (102 [68.0\%]), arthralgia (65 [43.3\%]) and back pain (33 [22.0\%]). Arthralgia, which was mostly notable at wrist (25 [16.7\%]), ankle (24 [16.0\%]) and knee (23 [15.3\%]) joints, showed significant correlation with disease severity. There was severe myalgia according to NRS regardless of disease severity. The physical fatigue severity score was significantly higher in severe cases, whereas no relationship was found with mental fatigue score. Female patients with severe infection had lower grip strength with a mean value of $18.26 \mathrm{~kg}(P=.010)$ in dominant hand, whereas no relationship was found between disease severity and grip strength in male patients, but the mean values in both genders and in decades appears below the specified normative values. Lactate dehydrogenase (LDH) level and lymphocyte count were significantly correlated with lower grip strength. LDH, C-reactive protein (CRP) and D-dimer levels were above the normal range in patients with myalgia, arthralgia and fatigue.

CONCLUSIONS AND RELEVANCE Musculoskeletal symptoms are quite common aside from other multi-systemic symptoms in patients with COVID-19. Arthralgia, which is related to the disease severity, should be considered apart from myalgia. COVID-19 patients have severe ischemic myalgia regardless of the disease activity. Although there is a muscle weakness in all patients, the loss of muscle function is related with the disease activity especially in women. Muscular involvement in coronavirus disease is a triangle of myalgia, physical fatigue, and functional impairment.

\section{Introduction}

COVID-19 is an emerging disease that was declared as a pandemic by the World Health Organization (WHO) on 12 March. Up to date, 225.173 cases have been diagnosed as COVID-19 in Turkey, and 15.581 .009 cases globally [1, 2].

Musculoskeletal symptoms are quite common in patients with COVID-19 aside from other symptoms like fever, sore throat, dry cough, and dyspnea. Myalgia, arthralgia, and fatigue are the most common musculoskeletal symptoms; those have been reported with a peak ratio of $40 \%, 15 \%$, and $85 \%$ respectively $[3,4,5]$. Although they are totally different, myalgia and arthralgia was usually taken into account together in majority of studies [6]. There are many retrospective studies to present clinical aspects of the COVID-19 disease, still the involvement of the musculoskeletal system has not been deeply investigated, and there is lack of terminological clarity in terms of these symptoms. Myalgia is the most frequently used term to explain all of these musculoskeletal symptoms, and this can lead to some misunderstanding results in assessing clinical presentation of the disease [7]. Perhaps, the question should be asked here, "Is myalgia good enough to explain musculoskeletal involvement in patients with COVID-19?". Recent evidence is emerging on the musculoskeletal involvement [8], and our clinical experience at the University Pandemic Clinic also supported that those symptoms were considerably common and could be quite serious during the period of disease.

To date, the most concrete rational of this rheumatologic connection is a common inflammatory environment, in other words "a cytokine storm" caused by also infectious pathway of severe acute respiratory syndrome coronavirus 2 (SARS-CoV-2). IL-6 is the predominantly produced cytokine, as in response to exercise-induced destruction of muscle, and as part of the cytokine storm it can also induce muscle dysfunction [9]. Handgrip strength (HGS) is considered to be a non-invasive, simple, objective and reliable method for assessing muscle function [10].

The aim of the present study is to classify the symptoms of musculoskeletal system in COVID-19 patients, to evaluate myalgia, arthralgia and physical/mental fatigue with validated clinical scales, to assess handgrip muscle strength, and to examine the relationship of these parameters with the severity and laboratory findings of the disease. To our knowledge, this is the first study revealing a structured prospective musculoskeletal approach in COVID19 patients.

\section{Methods}

\section{Study design and participants}

This cross-sectional study was performed at IUC -Cerrahpaşa Pandemic Clinic which was assigned by the government to manage patients with COVID-19. Consecutive patients from May 15, 2020, to June 30, 2020, who had been hospitalized adults (aged $\geq 18$ years) with laboratory and radiological confirmation of SARS-CoV-2 according to WHO interim guidance were included into the study [11]. 
A confirmed case of COVID-19 was defined as a positive result on real-time reverse-transcription polymerase chain reaction analysis of throat swab specimens and/or radiologic assessments included chest CT according to Radiological Society of North America (RSNA) classification [12].

Written informed consents from all patients were provided prior to enrollment. The study was performed in accordance with the principles of the Declaration of Helsinki, and approved by both the research ethic committee of IUC and Republic of Turkey Ministry of Health.

One hundred fifty hospitalized patients with laboratory and/or radiologic confirmation of SARS-CoV-2 were included in the study.

\section{Data Collection}

Demographic data on age, sex, comorbidities (hypertension, diabetes, thyroid disease, cardiovascular and cerebrovascular disease, malignancy, chronic kidney disease and rheumatologic diseases) were collected. Typical symptoms from onset to hospital admission (fever, cough, dyspnea, loss of appetite, myalgia, fatigue, arthralgia, diarrhea, sore throat) were evaluated.

Routine laboratory investigations of patients during their hospitalizations (a complete blood cell count, alanine aminotransferase (ALT) and aspartate aminotransferase (AST) levels, creatinine and blood urea levels, D-dimer, ferritin, C-reactive protein (CRP), lactate dehydrogenase (LDH), procalcitonine, troponin T, creatine kinase (CK) and isoenzyme CK-MB and calcium (Ca) level were analyzed.

\section{Disease Severity}

Degree of severity of COVID-19 (severe vs nonsevere) at the time of data collection was defined by using the American Thoracic Society (ATS) guidelines for community-acquired pneumonia [13].

\section{Musculoskeletal Symptoms}

Myalgia and arthralgia localizations were interrogated in detail and severity of myalgia were calculated by numerical rating scale (NRS).

Since fatigue is a multifactorial phenomenon, we used visual analog scale (VAS) for assessing physical and mental fatigue, separately. Turkish version of the Chalder Fatigue Scale (CFS), which is created to measure the severity of fatigue, was also applied and scoring was done by bimodal system [14].

\section{Strength Measurements}

Handgrip strength (HGS) was measured by using a Jamar Hand Dynamometer (Jamar Hand Evaluation Kit, Sammons Preston Ins., Bolingbrook,IL) with patients seated, their elbow by their side and flexed to right angles, and a neutral wrist position [15]. Three measurements were performed for both side, and the mean score was recorded (dominancy was noted).

\section{Statistical Analysis}

All statistical analyses were performed using the XLStat-2011, version 1.01. Baseline characteristics were given as mean \pm standard deviation for normally distributed continuous, median and range for non-normal continuous and percentages for categorical data.

Differences between two groups with continuous data were tested with "independent samples t-test" where assumptions were satisfied, and with nonparametric Mann-Whitney U test where assumptions were not satisfied. To assess the significance of differences between groups with categorical data Pearson Chi-Square or Fisher's Exact Test were utilized in accordance with assumptions. For the continuous outcome variables, bootstrap confidence intervals were presented along with mean scores for non-normal data to assess the significance of the difference between two independent groups. A $p$ value $<0.05$ was accepted to be statistically significant.

\section{Results}

\section{Demographic and Clinical Characteristics}

This study was performed in 150 patients (77 [51.3\%] male and 73 [48.7\%] female) with a mean (SD) age of 53.17 (15.49). 103 patients (68.7\%) were nonsevere and $47(31.3 \%)$ patients were severe in terms of ATS guideline.

Demographic features, characteristics, and musculoskeletal symptoms of the patients in terms of disease severity are shown in table 1. Fifty-one (34.0\%) patients had at least one comorbidity, and hypertension (51 [34.0\%]), cardiovascular diseases (41 [27.3\%]) and diabetes (35 [23.3\%]) were relatively common. Among these diseases, only chronic renal disease had a significant importance in terms of COVID-19 severity.

Cardinal symptoms of our patients were listed as fatigue, myalgia, loss of appetite and cough, respectively.

\section{Laboratory Findings}

Laboratory parameters were listed in table 2 . Almost all laboratory parameters (except ALT, CK, and calcium) were significantly correlated with disease severity. With a median value of $800 \mathrm{mcL}$ lymphocyte count ([range, <1100]; $\mathrm{P}<.001$ ), $3900 \mathrm{mcL}$ white blood cell count (range, $[<4000]$; $\mathrm{P}<.001$ ), $82.0 \mathrm{mg} / \mathrm{L} \mathrm{C}$ - reactive protein ([range, 0-5]; $P<.001$ ), $0.146 \mathrm{ng} / \mathrm{mL}$ procalcitonin ([range, 0-0.5]; $\mathrm{P}<.001$ ) and $607 \mathrm{ng} / \mathrm{ml}$ ferritin level ([range, 30-400]; $P<.001)$ showed increased inflammatory response in patients with severe infection. Our patients with severe disease had higher level of $D$-dimer, which is an indicative marker of coagulation system with a median value of $1.69 \mathrm{mg} / \mathrm{L}$ ([range, $0-0.5]$; $\mathrm{P}<.001$ ) in comparison with patients with nonsevere infection. In order to determine 
multiple organ involvement, alanine aminotransferase and aspartate aminotransferase levels for liver, creatinine and blood urea levels for kidneys were assessed. Level of $30 \mathrm{IU} / \mathrm{L} \mathrm{ALT}$ (range, < 33), $32 \mathrm{IU} / \mathrm{L} \mathrm{AST}$ ([range, < 32]; $\mathrm{P}=.029$ ) and $42 \mathrm{mg} / \mathrm{dL}$ blood urea ([range, 17-49]; $\mathrm{P}<.001), 1.09 \mathrm{mg} / \mathrm{dL} \mathrm{creatinine}$ ([range, 0.5-0.9];

$\mathrm{P}=.014)$ were significantly higher in severe cases. As muscular system markers, creatinine kinase, lactate dehydrogenase and troponin- $\mathrm{T}$ levels were evaluated. CK median level was $111 \mathrm{IU} / \mathrm{L}$ (range, $>170 \mathrm{IU} / \mathrm{L}$ ), and its isoenzyme CK-MB was $33.8 \mathrm{U} / \mathrm{L}$ (range, > 25) with no severity correlation. With median value of $0.015 \mathrm{ng} / \mathrm{ml}$ troponin-T ([range, < 0.014]; $\mathrm{P}<.001$ ) and $417 \mathrm{IU} / \mathrm{L} \mathrm{LDH}$ ([range, < 250]; $\mathrm{P}<.001$ ) were significantly correlated with severe infection.

\section{Musculoskeletal Symptoms}

The most common musculoskeletal symptom was fatigue (133 [85.3\%]), followed by myalgia (102 [68.0\%]), arthralgia (65 [43.3\%]) and back pain (33 $[22.0 \%])$. Among these symptoms only arthralgia has been found to be significantly related to disease severity $(P=.024)$, (table 1$)$.

Distribution of musculoskeletal symptoms was shown in table 3. Majority of the patients had widespread myalgia (62 [41.3\%]). Thirty-three (22.0\%) patients had back pain regardless of myalgia. Arthralgia was mostly notable at wrist (25 [16.7\%]), ankle (24[16.0\%]) and knee (23 [15.3\%]) joints.

There was no correlation between myalgia and disease severity in patients with COVID-19, according to NRS. The mean NRS score was found 7.19 (range, $6.71-7.68$ ) in nonsevere, and 7.21 (range, $6.21-8.13$ ) in severe cases with a total mean value of 7.20 indicating severe myalgia (range, 6.76 - 7.64 ), (data not shown).

In 133 patients who affirmed fatigue as a symptom; Chalder Fatigue Scale and physical and mental state VAS-F were performed (table 4). 120 of them have been confirmed by CFS. The mean value of physical fatigue severity score was significantly higher (7.70 [range, $7.09-8.26$ ]; $P=.048)$ in severe cases than in nonsevere cases (6.94 [range, $6.43-7.41])$. There was no relationship between disease severity and mental fatigue severity score.

The grip strength in kilograms according to age groups, regardless of hand dominancy, for women and men are presented in table 5.

Disease severity has been found to be correlated with the grip strength in dominant hand for women, significantly. Female patients with severe infection had lower grip strength with a mean value of $18.26 \mathrm{~kg}(P=.010)$ in dominant hand, whereas no relationship was found between disease severity and grip strength in male patients (table 6).

The relationship between musculoskeletal symptoms and laboratory findings of patients with COVID-19 is shown in table 7 . LDH with a mean value of 323 IU/L (293-360) and $315 \mathrm{IU} / \mathrm{L}$ (280-353), were above the normal range in patients with myalgia and arthralgia, respectively. The mean value of CRP (75.48 $\mathrm{mg} / \mathrm{L}$ [55.42-100.57]) for myalgia and (80.61 mg/L [52.24-118.09]) for arthralgia, which were above the normal level, were correlated with COVID-19. In terms of D-dimer levels for myalgia (3.19 mg/L [1.63-5.25]) and for arthralgia (3.23 mg/L [1.62-5.35]) were found to be related.

In terms of fatigue; there was a significant correlation with LDH (339 IU/L [range, 311-371]; $\mathrm{P}=.030)$ and CRP (74.49 mg/L [range, 58.50-91.70]; $\mathrm{P}=.027)$. Ddimer level had also been found higher in patients with fatigue (3.22 mg/L [1.93-4.65]). No correlation was found between CK levels and myalgia.

Handgrip strength values of patients were compared with normative data according to age and gender, grouped as normal and lower [16]. Laboratory correlations with normal and lower grip strength related to gender were shown in table 8.

LDH was significantly higher with a mean value of $361.49 \mathrm{IU} / \mathrm{L}$ ([range, $318.53-408.34], \mathrm{P}=.027$ ) and lymphocyte count was lower with a mean value of 1097.67 count/mcL ([range, 939.91 - 1291.03]; $\mathrm{P}=.003$ ) in female patients, and both laboratory parameters were correlated with lower grip strength. As an inflammatory marker, CRP (74.08 mg/L [range, 52.39 - 96.18]; $P=.020)$ and ferritin (399.49 $\mathrm{ng} / \mathrm{L}$ [range, 258.39 - 571.07]; $\mathrm{P}=.042)$ were also related with lower grip strength in female patients. No correlation was found between handgrip strength and laboratory findings in male patients.

\section{Discussion}

Coronaviruses are a large family of viruses that are known to cause mild to moderate respiratory tract infection. A novel Coronavirus was identified in this century and called SARS-CoV-2, and the name of the disease caused by this virus announced as COVID-19. Although some cases may be asymptomatic or present with diarrhea or anorexia, the majority of them present with the complaint of fever, cough and generalized weakness and myalgia [17]. However, in these patients, especially the musculoskeletal system complaints have not been adequately investigated, besides, our clinical experience with CoVID-19 patients supported that those symptoms were considerably common and could be quite serious during the period of disease. Therefore, the purposes of this study were to reveal musculoskeletal complaints, examine the handgrip strengths and also to look into the relation between the severity and laboratory findings of the disease with all these parameters.

Arthralgia is a quite common symptom in our study, involving mostly wrist, ankle and knee joints in patients with COVID-19. On the other hand, prevalence of arthralgia has been reported relatively low in patients with COVID-19 [5]. However, this prevalence data based on retrospective studies, and there is usually an overlap with myalgia [6]. In the present study, arthralgia is directly correlated to the disease severity. According to our data, it was related to plasma CRP, which is a proinflammatory marker, and a valuable tool in the current COVID-19 pandemic.

Myalgia is one of the most frequent symptoms in our cases with a 7.20 symptom severity score indicating "severe myalgia".

The term "muscle damage" or even "muscle injury" has been widely used to explain muscle involvement in COVID-19 patients although there is no enough data to support this statement [18]. None of our patients, even in cases with severe myalgia and fatigue, had findings of rhabdomyolysis indicating the rapid breakdown of skeletal muscle. Moreover, there is only one case report addressing rhabdomyolysis as a potential late complication of COVID-9 [19].

Page $4 / 10$ 
LDH, which releases from cells or organs in response to tissue injury in the absence of overt cell death [20], was the most related marker in terms of myalgia and fatigue in our study. This finding supported by a new theory asserting that COVID-19 can cause musculoskeletal pain with completely different mechanisms rather than other viral infections. Increased LDH and anaerobic glycolysis lead to an increase in lactate level in muscles, and this can cause hypoxia and ischemic muscle pain. That is why, as the virus load decreases; the oxygenation of erythrocytes increases, muscle lactate level decreases, and pain relievers [21,22]. Increased expression of endothelial cell adhesion molecules, which is related to coagulopathy in COVID-19 patients [23], cause hypoxia and expressed by increased D-dimer level, which was also related with myalgia and fatigue in our study. In brief, it is possible to state that patients with COVID-19 clinically present ischemic myalgia.

$\mathrm{CK}$, which is a mitochondrial protein, is thought to increase in case of injury with absence of cell death. However, pathologic confirmation was not demonstrated and additively, electron microscopic examination of ischemic area showed cells were severely damaged and necrotic [24]. This can also explain why there was no relationship between myalgia and CK indicating muscle damage in our cases. Therefore, our results indicate that muscle involvement in COVID-19 disease is mostly related to a functional impairment rather than a real tissue damage.

Some of the patients, even those who appear to have only mild symptoms initially, also end up struggle with fatigue or muscle pain that linger for weeks or months [25]. Fatigue was the most frequent finding among all of the symptoms in our cases. However, the correlation with disease activity was found only for the physical fatigue rather than mental fatigue, and this made think us that, there was a relevance between fatigue and the pathogenesis of SARS-CoV-2 infection. Patients mostly experience muscle loss, which can result in direct physical fatigue.

There are some possible causal relationships between SARS-CoV-2 and muscle wasting. First of all, increased proinflammatory cytokines in COVID-19 disease, especially elevated IL-6 levels can induce muscle atrophy by acting through the Jak/Stat3 pathway [26]. Also observations from other researches mention that, high levels of IL-6 are associated with the age-related decline in muscle function due to sarcopenia [27].

On second thought, the ubiquitin proteasome system (UPS) has been shown to play an important role in mediating muscle wasting. There is also a link between Corona virus and myogenic proteins, and it has been shown that Ubiquitin-Proteasome System (UBS) plays an important role in multiple steps of the CoV infection cycle [28]. We do not yet know; how much role SARS-CoV-2 plays in the catabolic program in skeletal muscle that is highly relevant to its infectious pathway. Besides, ACE2 protein, which is the functional receptor for the virus, is also expressed in muscles, and SARS-CoV-2 may infect other tissues aside from the lungs [29].

Grip strength can be used as a measure of fatigue. Hypoxia may sensitize skeletal muscle to fasting-induced muscle atrophy [30]. Handgrip strength measurement is also recommended to estimate the overall impairment in COVID-19 [31]. This method correlates closely with measures of muscle strength from other muscle groups, including the lower limbs [32]. The average for grip strength of men is higher than that of women [33].

Normative data for HGS values has been studied in the literature and expected normal values according to the age ranges and gender are specified [16]. When compared with the current normative data, the average HGS values of the patients in our study, the mean values in both genders and in decades appears below the specified normative values. This indicates that all patients develop a dysfunction in muscle function. When the HGS values of the patients were compared with the disease activity, the average HGS values of women decrease significantly with the disease activity. Likewise, Crp and ferritin values, which are inflammatory markers that show disease activity, are found to be correlated with lower grip strength in women. According to our current findings, although there is a loss of muscle function in both sexes and all age groups, this loss of muscle function was correlated with the disease activity especially in women.

Considering current clinical musculoskeletal symptoms of COVID-19 disease, and the possible relationship between the virus and muscle metabolism, a functional impairment can be expected in patients during the disease.

Presumed limitations of this study include, having a relatively small sample in order to study the data in each age group in more detail. More studies with a larger and more diverse sample are needed to support our results.

\section{Conclusions}

Musculoskeletal symptoms are quite common aside from other multi-systemic symptoms in patients with COVID-19. Arthralgia is related to disease severity, and should be considered apart from myalgia. COVID-19 patients have severe myalgia regardless of the disease activity. Muscle involvement in COVID-19 disease seems to be related to hypoxia leading to severe ischemic myalgia and physical fatigue. Although there is a muscle weakness in all patients, the loss of muscle function is related with the disease activity especially in women. Muscular involvement in corona disease is a triangle of myalgia, physical fatigue, and functional loss.

\section{Declarations}

\section{Author Disclosures:}

There was no external funding in the preparation of this manuscript.

Each author certifies that he or she, or a member of his or her immediate family, has no commercial association (i.e., consultancies, stock ownership, equity interest, patent/licensing arrangements, etc.) that might pose a conflict of interest in connection with the submitted manuscript.

\section{Compliance with Ethical Standards:}


Ethical approval: All procedures performed in studies involving human participants were in accordance with the ethical standards of the institutional and/or national research committee and with the 1964 Helsinki declaration and its later amendments or comparable ethical standards.

ACKNOWLEDGEMENT: We would like to thank Mr. Erkan Pekerkan from MOTA Tıpsal Araştırmalar for his assistance with statistical analysis.

\section{References}

1. Current number of COVID-19 cases in Turkey. Republic of TurkeyMinistry of Accessed July 25, 2020. https://covid19.saglik.gov.tr

2. Globally confirmed cases of COVID-19. World Health Organization. Accessed July 25, 2020. https://covid19.who.int

3. Chen G, Wu D, Guo W, et al. Clinical and immunological features of severe and moderate coronavirus disease 2019. J Clin Invest. 2020;130(5):2620-2629. doi:10.1172/JCl137244

4. Bai Y, Yao L, Wei T, et al. Presumed Asymptomatic Carrier Transmission of COVID-19. 2020;323(14):1406-1407. doi:10.1001/jama.2020.2565

5. Schett, G., Manger, B., Simon, D. et al.COVID-19 revisiting inflammatory pathways of arthritis. Nat Rev Rheumatol (2020). https://doi.org/10.1038/s41584020-0451-z

6. Cipollaro L, Giordano L, Padulo J, Oliva F, Maffulli N. Musculoskeletal symptoms in SARS-CoV-2 (COVID-19) patients. J Orthop Surg Res. 2020;15(1):178. Published 2020 May 18. doi:10.1186/s13018-020-01702-w

7. Lippi G., Wong J, Brandon M.H. Myalgia may not be associated with severity of coronavirus disease 2019. World J Emerg Med 2020;11(3):193-194

8. Abdullahi A, Candan SA, Abba MA, et al. Neurological and Musculoskeletal Features of COVID-19: A Systematic Review and Meta-Analysis. Front Neurol. 2020;11:687. Published 2020 Jun 26. doi:10.3389/fneur.2020.00687

9. Radigan KA, Nicholson TT, Welch LC, et al. Influenza A Virus Infection Induces Muscle Wasting via IL-6 Regulation of the E3 Ubiquitin Ligase Atrogin-1. $J$ Immunol. 2019;202(2):484-493. doi:10.4049/jimmunol.1701433 Bohannon RW.

10. Dynamometer measurements of hand-grip strength predict multiple outcomes. Percept Mot Skills. 2001;93(2):323-328. doi:10.2466/pms.2001.93.2.323

11. World Health Organization. Clinical management of severe acute respiratory infection when Novel coronavirus (nCoV) infection is suspected: interim guidance. January 2020. Accessed February 5, 2020. https://www.who.int/internal-publications- detail/clinical-management-of-severe-acute-respiratoryinfection-when-novel-coronavirus-(ncov)-infection-is-suspected

12. Simpson S, Kay FU, Abbara S, et al. Radiological Society of North America Expert Consensus Statement on Reporting Chest CT Findings Related to COVID-19. Endorsed by the Society of Thoracic Radiology, the American College of Radiology, and RSNA - Secondary Publication. $J$ Thorac Imaging 2020;35(4):219-227. doi:10.1097/RTI.0000000000000524

13. Metlay JP, Waterer GW, Long AC, et al. Diagnosis and treatment of adults with community-acquired pneumonia: an official clinical practice guideline of the American Thoracic Society and Infectious Disease Society of America. Am J Respir Crit Care Med. 2019;200(7):e45-e67. doi:10. 1164/rccm.2019081581ST

14. Cella M, Chalder T. Measuring fatigue in clinical and community settings. J Psychosom Res. 2010;69(1):17-22.

15. Mathiowetz V, Weber K, Volland G, Kashman N (1984) Reliability and validity of pinch and grip strength evaluations. J Hand Surg 9A: 222-226

16. Massy-Westropp NM, Gill TK, Taylor AW, Bohannon RW and Hill CL. Hand Grip Strength: age and gender stratified normative data in a population-based study. BMC Research Notes 2011, 4:127

17. Heydari K, Rismantab S, Shamshirian A, et al. Clinical and paraclinical characteristics of COVID-19 patients: a systematic review and meta-analysis. 2020 Mar 30. https://doi.org/10.1101/2020.03.26.20044057

18. Mao L, Jin H, Wang M, et al. Neurologic Manifestations of Hospitalized Patients With Coronavirus Disease 2019 in Wuhan, China [published online ahead of print, 2020 Apr 10]. JAMA Neurol. 2020;77(6):1-9. doi:10.1001/jamaneurol.2020.1127

19. Jin M, Tong Q. Rhabdomyolysis as Potential Late Complication Associated with COVID-19. Emerg Infect Dis. 2020;26(7):1618-1620. https://dx.doi.org/10.3201/eid2607.200445

20. Doty $\mathrm{DH}$, Bloor CM, Sobel BE. Altered tissue lactic dehydrogenase activity after exercise in the rat. Am J Physiol 1971;30:548 -51.

21. Kucuk A, Cumhur Cure M, Cure E. Can COVID-19 cause myalgia with a completely different mechanism? A hypothesis. Clin Rheumatol. 2020;39(7):21032104. doi:10.1007/s10067-020-05178-1

22. Queme LF, Ross JL, Jankowski MP. Peripheral Mechanisms of Ischemic Myalgia. Front Cell Neurosci. 2017;11:419. Published 2017 Dec 22. doi:10.3389/fncel.2017.00419

23. Ming Tong, Yu Jiang, Da Xia, Ying Xiong. Elevated Serum Endothelial Cell Adhesion Molecules Expression in COVID-19 Patients. J Infect Dis. 2020 Jun 25: jiaa349

24. Ishikawa Y, Saffitz JE, Mealman TL, Grace AM, Roberts R. Reversible myocardial ischemic injury is not associated with increased creatine kinase activity in plasma. Clin Chem 1997;43:467-75.

25. Carfi A, Bernabei R, Landi F; Gemelli Against COVID-19 Post-Acute Care Study Group. Persistent Symptoms in Patients After Acute COVID-19. 2020 Jul 9:e2012603.

26. Moresi V, Adamo S, Berghella L. The JAK/STAT Pathway in Skeletal Muscle Pathophysiology. Front Physiol. 2019;10:500. Published 2019 Apr 30. doi:10.3389/fphys.2019.00500

27. Schaap LA, Pluijm SM, Deeg DJ, Visser M. Inflammatory markers and loss of muscle mass (sarcopenia) and strength. Am J Med. 2006;119(6):526.e9526.e5.26E17. doi:10.1016/j.amjmed.2005.10.049 
28. Raaben M., et al. The Ubiquitin-Proteasome System plays an Important Role during Various Stages of the Coronavirus Infection Cycle. Journal of Virology, Aug 2010, p.7869-7879

29. Li, M., Li, L., Zhang, Y. et al.Expression of the SARS-CoV-2 cell receptor gene ACE2 in a wide variety of human tissues. Infect Dis Poverty 9 , 45 (2020). https://doi.org/10.1186/s40249-020-00662-x

30. De Theije CC, Schols A, Lamers WH, Kohler SE, Langen RCJ. Hypoxia sensitizes skeletal muscle to fasting-induced muscle atrophy; role of AMPK activation. European Respiratory Journal. 2015;46:2.

31. Ekiz T, Kara M, Özçakar L. Measuring grip strength in COVID-19: A simple way to predict overall frailty/impairment. Heart Lung. 2020 May 28:S01479563(20)30234-X

32. Samuel D, Wilson K, Martin HJ, Allen R, Sayer AA, Stokes M. Age-associated changes in hand grip and quadriceps muscle strength ratios in healthy adults. Aging Clin Exp Res 2012;24:245e50.

33. Mathiowetz V, Kashman N, Volland G, Weber K, Dowe M, Rogers S (February 1985). "Grip and pinch strength: normative data for adults". Arch Phys Med Rehabil. 66 (2): 69-74. PMID 3970660. Archived from the original on 2011-07-08. Retrieved 2010-12-06

\section{Tables}




\begin{tabular}{|c|c|c|c|c|c|c|c|}
\hline & \multicolumn{6}{|c|}{ Freq. (\%) or Mean (SD) } & \multirow[b]{4}{*}{$P$-Value } \\
\hline & \multicolumn{2}{|c|}{ Non-severe } & \multicolumn{2}{|c|}{ Severe } & \multicolumn{2}{|c|}{ Total } & \\
\hline & \multicolumn{2}{|c|}{$(n=103)$} & \multicolumn{2}{|c|}{$(n=47)$} & \multicolumn{2}{|c|}{$(n=150)$} & \\
\hline Demographic Features & No & $\%$ & No & $\%$ & No & $\%$ & \\
\hline Age, mean (SD), years & $50.60(15.31)$ & & $58.81(14.50)$ & & $53.17(15.49)$ & & \\
\hline \multicolumn{8}{|l|}{ Age, years } \\
\hline $20-29$ & 12 & 11.7 & 3 & 6.4 & 15 & 10 & $0,05 *$ \\
\hline $30-39$ & 10 & 9.7 & 3 & 6.4 & 13 & 9 & \\
\hline $40-49$ & 24 & 23.3 & 5 & 10.6 & 29 & 19 & \\
\hline $50-59$ & 31 & 30.1 & 12 & 25.5 & 43 & 29 & \\
\hline $60-69$ & 13 & 12.6 & 14 & 29.8 & 27 & 18 & \\
\hline 70 and above & 13 & 12.6 & 10 & 21.3 & 23 & 15 & \\
\hline \multicolumn{8}{|l|}{ Gender } \\
\hline Female & 51 & 49.5 & 22 & 46.8 & 73 & 48.7 & 0.861 \\
\hline Male & 52 & 50.5 & 25 & 53.2 & 77 & 51.3 & \\
\hline \multicolumn{8}{|l|}{ Comorbidities } \\
\hline Any & 66 & 64.1 & 33 & 70.2 & 99 & 66.0 & 0.462 \\
\hline Hypertension & 35 & 34.0 & 16 & 34.0 & 51 & 34.0 & 0.994 \\
\hline Diabetes & 25 & 24.3 & 10 & 21.3 & 35 & 23.3 & 0.687 \\
\hline Cardiovascular Disease & 25 & 24.3 & 16 & 34.0 & 41 & 27.3 & 0.213 \\
\hline Cerebrovascular Disease & 1 & 1.0 & 3 & 6.4 & 4 & 2.7 & 0.091 \\
\hline Malignancy & 6 & 5.8 & 6 & 12.8 & 12 & 8.0 & 0.194 \\
\hline Chronic Renal Disease & 1 & 1.0 & 5 & 10.6 & 6 & 4.0 & $0.012 *$ \\
\hline Thyroid Disease & 7 & 6.8 & 2 & 4.3 & 9 & 6.0 & 0.720 \\
\hline Rheumatoid Arthritis & 0 & 0.0 & 2 & 4.3 & 2 & 1.3 & 0.097 \\
\hline Spondyloarthropathy & 1 & 1.0 & 0 & 0.0 & 1 & 0.7 & 1.000 \\
\hline Other & 14 & 13.6 & 7 & 14.9 & 21 & 14.0 & 0.831 \\
\hline \multicolumn{8}{|l|}{ Typical Symptoms } \\
\hline Fever & 53 & 51.5 & 31 & 66.0 & 84 & 56.0 & 0.097 \\
\hline Cough & 62 & 60.2 & 31 & 66.0 & 93 & 62.0 & 0.500 \\
\hline Loss of Appetite & 66 & 64.1 & 34 & 72.3 & 100 & 66.7 & 0.319 \\
\hline Diarrhea & 38 & 36.9 & 20 & 42.6 & 58 & 38.7 & 0.509 \\
\hline Sore Throat & 44 & 42.7 & 10 & 21.3 & 54 & 36.0 & $0.011 *$ \\
\hline Dyspnea & 44 & 42.7 & 28 & 59.6 & 72 & 48.0 & 0.055 \\
\hline \multicolumn{8}{|l|}{ Musculoskeletal Symptoms } \\
\hline Fatigue & 89 & 86.4 & 44 & 93.6 & 133 & 85.3 & 0.196 \\
\hline Myalgia & 74 & 71.8 & 28 & 59.6 & 102 & 68.0 & 0.135 \\
\hline Arthralgia & 51 & 49.5 & 14 & 29.8 & 65 & 43.3 & $0.024 *$ \\
\hline Backpain & 23 & 22.3 & 10 & 21.3 & 33 & 22.0 & 0.885 \\
\hline
\end{tabular}




\begin{tabular}{|c|c|c|c|c|c|c|c|}
\hline \multirow[b]{3}{*}{ ngs } & \multicolumn{6}{|c|}{ Median (Range) or Freq. (\%) } & \multirow[b]{3}{*}{$P$-Value } \\
\hline & \multicolumn{2}{|l|}{ Non-severe $(n=103)$} & \multicolumn{2}{|c|}{ Severe $(n=47)$} & \multicolumn{2}{|l|}{ Total $(n=150)$} & \\
\hline & No & $\%$ & No & $\%$ & No & $\%$ & \\
\hline$\overline{\mathrm{nt} / \mathrm{mcL})}$ & $5000(2900-18000)$ & & $3900(1300-18500)$ & & $4550(1300-18500)$ & & $<0.001 *$ \\
\hline$\overline{\mathrm{e}(\text { count } / \mathrm{mcL})}$ & $1300(100-6100)$ & & $800(300-2000)$ & & $1200(100-6100)$ & & $<0.001 *$ \\
\hline 1100), freq. & 21 & 20.4 & 32 & 68.1 & 53 & 35.3 & $<0.001^{*}$ \\
\hline il (count/mcL) & $2600(900-15500)$ & & $2500(100-18000)$ & & $2500(100-18000)$ & & 0.303 \\
\hline :ount/mcL) & $188000(85-651000)$ & & $148000(10500-484000)$ & & $182800(185-651000)$ & & $<0.001 *$ \\
\hline (dL) & $31(13-113)$ & & $42(7-227)$ & & $34(7-227)$ & & $<0.001 *$ \\
\hline (mg/dL) & $0.91(0.54-8.44)$ & & $1.09(0.25-13.29)$ & & $0.965(0.25-13.29)$ & & $0.014^{*}$ \\
\hline ) & $26.6(10.0-647.0)$ & & $32.0(13.0-239.0)$ & & $28.050(10.0-647.0)$ & & $0.029 *$ \\
\hline & $24.7(2.9-414.0)$ & & $30.0(6.3-295.0)$ & & $27.0(2.9-414.0)$ & & 0.478 \\
\hline L) & $21.76(0.26-988.0)$ & & $82.00(1.11-395.00)$ & & $33.35(0.26-988.00)$ & & $<0.001 *$ \\
\hline$\geq 5$ ), freq. & 79 & 76.7 & 44 & 93.6 & 123 & 82.0 & $0.012 *$ \\
\hline 」) & $254(70-793)$ & & $417(186-929)$ & & $287(70-929)$ & & $<0.001 *$ \\
\hline \multirow[t]{2}{*}{$\geq 250$ ), freq. } & 53 & 51.5 & 39 & 83.0 & 92 & 61.3 & $<0.001^{*}$ \\
\hline & $103(11-1080)$ & & $111(24-2181)$ & & $106(11-2181)$ & & 0.921 \\
\hline$\geq 170$ ), freq. & 25 & 24.3 & 13 & 27.7 & 38 & 25.3 & 0.658 \\
\hline /L) & $24.0(0.1-160.0)$ & & $33.8(14.0-102.0)$ & & $26.25(0.1-160.0)$ & & $0.002 *$ \\
\hline$\geq 25$ ), freq. & 48 & 46.6 & 32 & 68.1 & 80 & 53.3 & $0.014^{*}$ \\
\hline$(\mathrm{mg} / \mathrm{L})$ & $0.61(0.06-77.68)$ & & $1.69(0.27-59.65)$ & & $0.85(0.06-77.68)$ & & $<0.001^{*}$ \\
\hline$\geq 0.50$ ), freq. & 64 & 62.1 & 43 & 91.5 & 107 & 71.3 & $<0.001^{*}$ \\
\hline $\mathrm{lg} / \mathrm{ml})$ & $180.40(1.29-1671.0)$ & & $607.00(3.18-3216)$ & & $266.00(1.29-3216)$ & & $<0.001 *$ \\
\hline$\geq 400$ ), freq. & 25 & 24.3 & 31 & 66.0 & 56 & 37.3 & $<0.001 *$ \\
\hline $\mathrm{T}(\mathrm{ng} / \mathrm{ml})$ & $0.006(0.000-0.127)$ & & $0.015(0.000-1.060)$ & & $0.007(0.000-1.060)$ & & $<0.001 *$ \\
\hline$\geq 0,014)$, freq. & 21 & 20.4 & 25 & 53.2 & 46 & 30.7 & $<0.001^{*}$ \\
\hline $\min (\mathrm{ng} / \mathrm{ml})$ & $0.061(0.000-38.790)$ & & $0,146(0.033-58.50)$ & & $0.0705(0.000-58.500)$ & & $<0.001 *$ \\
\hline$\geq 0,500$ ), freq. & 7 & 6.8 & 9 & 19.1 & 16 & 10.7 & $0.023 *$ \\
\hline $\mathrm{mg} / \mathrm{dL})$ & $8.9(7.8-9.9)$ & & $8.6(0.9-10.5)$ & & $8.8(0.9-10.5)$ & & $<0.001 *$ \\
\hline
\end{tabular}

\begin{tabular}{|l|c|c|}
\hline \multicolumn{3}{|l|}{ Table 3. Distribution of Musculoskeletal Pain } \\
\hline \multicolumn{3}{|l|}{ Total (N= 150) } \\
\hline & No & \% \\
\hline Myalgia Localization & & \\
\hline Widespread & 62 & 41.3 \\
\hline Local & 20 & 13.3 \\
\hline \multicolumn{3}{|c|}{} \\
\hline Arthralgia Localization & 25 & 16.7 \\
\hline Wrist & 10 & 6.7 \\
\hline Elbow & 6 & 4.0 \\
\hline Shoulder & 4 & 2.7 \\
\hline Hip & 23 & 15.3 \\
\hline Knee & 24 & 16.0 \\
\hline Ankle & 5 & 3.3 \\
\hline Widespread &
\end{tabular}

Table 4. Evaluation of Fatigue with Chalder Fatigue Scale and VAS-F $\dagger$

\begin{tabular}{|c|c|c|c|c|c|c|c|}
\hline & \multicolumn{6}{|c|}{ Freq. (\%) } & \\
\hline & \multirow{2}{*}{\multicolumn{2}{|c|}{$\begin{array}{c}\text { Non-severe } \\
(n=103)\end{array}$}} & \multirow{2}{*}{\multicolumn{2}{|c|}{$\begin{array}{c}\text { Severe } \\
(n=47)\end{array}$}} & \multicolumn{2}{|l|}{ Total } & \\
\hline & & & & & $(n=150)$ & & \\
\hline Characteristic & No & $\%$ & No & $\%$ & No & $\%$ & $P$-Value \\
\hline \multicolumn{8}{|l|}{ Chalder Fatigue Scale (Bimodal) } \\
\hline Non-Fatigue & 24 & 23.3 & 6 & 12.8 & 30 & 20.0 & \multirow[t]{2}{*}{$0.135^{*}$} \\
\hline Fatigue & 79 & 76.7 & 41 & 87.2 & 120 & 80.0 & \\
\hline \multicolumn{8}{|c|}{ Mean (Confidence Interval) or Median (Range) } \\
\hline Physical Fatigue VAS, median & $7(1-10)$ & & $8(3-10)$ & & $8(1-10)$ & & 0.075 \\
\hline Phys. Fatigue VAS, mean (bootstrap CI) & $6.94(6.43-7.41)$ & & $7.70(7.09-8.26)$ & & $7.20(6.76-7.59)$ & & $0.048^{*}$ \\
\hline Mental Fatigue VAS, median & $6(0-10)$ & & $7.5(0-10)$ & & $7(0-10)$ & & 0.318 \\
\hline Ment. Fatigue VAS, mean (bootstrap CI) & $5.64(4.89-6.34)$ & & $6.41(5.41-7.35)$ & & $5.89(5.27-6.55)$ & & 0.215 \\
\hline
\end{tabular}


Table 5. Grip Strength Right - Left Hand by Age and Gender

\begin{tabular}{|c|c|c|c|c|c|c|}
\hline \multirow{2}{*}{} & \multicolumn{3}{|c|}{ Women } & \multicolumn{3}{c|}{ Men } \\
\cline { 2 - 7 } & \multicolumn{3}{|c|}{ Mean \pm SD } & \multicolumn{3}{c|}{ Mean \pm SD } \\
\hline Age & Right & Left & BMI & Right & Left & BMI \\
\hline $20-29$ & $24.94 \pm 5.77$ & $25.94 \pm 5.65$ & $22.2 \pm 4.10$ & $42.33 \pm 12.07$ & $42.98 \pm 9.74$ & $23 \pm 3.30$ \\
\hline $30-39$ & $22.23 \pm 6.02$ & $21.75 \pm 5.91$ & $27.4 \pm 2.60$ & $41.57 \pm 21.83$ & $41.04 \pm 21.31$ & $24.6 \pm 4.70$ \\
\hline $40-49$ & $25.56 \pm 9.37$ & $22.87 \pm 11.19$ & $30.6 \pm 7.10$ & $38.93 \pm 10.24$ & $39.73 \pm 10.55$ & $28.9 \pm 3.90$ \\
\hline $50-59$ & $21.14 \pm 8.03$ & $19.92 \pm 6.46$ & $30.9 \pm 5.50$ & $41.5 \pm 10.13$ & $39.94 \pm 10.42$ & $30.1 \pm 4.20$ \\
\hline $60-69$ & $20.42 \pm 5.84$ & $21.25 \pm 5.84$ & $29.8 \pm 6.30$ & $34.41 \pm 10.17$ & $33.16 \pm 10.16$ & $29.7 \pm 4.90$ \\
\hline $70+$ & $16.71 \pm 5.57$ & $15.56 \pm 5.34$ & $29.7 \pm 5.80$ & $24.21 \pm 13.12$ & $22.21 \pm 10.80$ & $25.5 \pm 4.50$ \\
\hline
\end{tabular}

\begin{tabular}{|l|l|c|c|c|c|c|}
\hline \multicolumn{7}{|c|}{ Table 6. Grip Strength in Dominant Hand by Gender and Disease Severity } \\
\hline & Confidence Interval (Bootstrap) \\
\cline { 1 - 5 } Gender & Disease Severity & N & Mean & Lower & Upper & Sig. \\
\hline Female & Non-severe & 51 & 23.37 & 21.45 & 25.48 & $0.010^{*}$ \\
\hline & Severe & 22 & 18.26 & 15.19 & 21.68 & \\
\hline & Total & 73 & 21.83 & 20.06 & 23.85 & \\
\hline & Non-severe & 52 & 37.67 & 33.42 & 41.39 & \multirow{2}{*}{0.492} \\
\hline & Severe & 25 & 35.40 & 29.56 & 40.89 & \\
\hline & Total & 77 & 36.93 & 34.06 & 39.85 & \\
\hline
\end{tabular}

\begin{tabular}{|c|c|c|c|c|c|c|c|c|c|c|c|c|c|c|c|}
\hline \multirow[b]{3}{*}{ Lab Fir } & \multicolumn{14}{|c|}{ Mean (Bootstrap CI) or Freq. (\%) } & \multirow{3}{*}{$\begin{array}{l}=150) \\
\\
\\
\quad \% \text {-Value }\end{array}$} \\
\hline & \multicolumn{2}{|c|}{ Myalgie } & 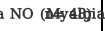 & \multicolumn{3}{|c|}{ YES $(n=10$ atal $(n=150)$ Arthral } & \multicolumn{3}{|c|}{ 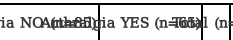 } & 150) Fatigu & \multicolumn{2}{|c|}{ NO (Iratigh } & \multicolumn{2}{|c|}{ 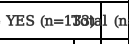 } & \\
\hline & dings & $v_{p}$ & lue & value & value & op-Valde & evalue $\%$ & value & value & $\mathscr{P P}$-Valde & velue & of & lue $\%$ v & Vilue & \\
\hline LDH (II) & /LB,34 & 310 & - $33153(29 \beta$ & 60833 (30) & - $\$ 589$ & 28347 (31) & $\$ 66315(280$ & - \$53833 (30) & $7-5880$ & d. $24586(25)$ - & 18339 & & 71333307 - & 5880. & $.030^{*}$ \\
\hline (high & $=238$ ). fre & q. & 2.97 & $\$ 5.992$ & 1.3. & .0453 & $\$ 3.538$ & 58.592 & d1.33 & .5283 & 6.579 & & 9.492 & 1.38 & .173 \\
\hline CK (IU) & L) 194 (12 & 7 . & $93171(13 \beta$. & $=10178\left(14 p^{2}\right.$ & -2160. & $65 \mathrm{~m} 6(13 \bar{\beta}$ & $444368(127$. & - \$19178 (14 & 160 & d. 64844 (104 - & $92183(14$ & & 27178 (14) - & 160 . & .235 \\
\hline (high & $=17(0) \cdot \mathrm{fre}$ & q. 2 & 9.224 & 3.538 & 25.37. & 4520 & 25.916 & 24.638 & 5.33 & 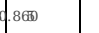 & 9.433 & & 1.88 & 5.3. & .768 \\
\hline Tropon & n To (niganid & 01 & $-\cos .002 x \phi .0$ & $0 \beta$ - (10)2nxd. & 01 1 - d & 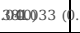 & $.017-0.056 \times \phi .0$ & $006-0.0228 x \phi$ & $.014-d$ & d.37mog 18 ( $\phi .0$ & $11-(0.026)$ & .01 & $-(0.0203) \times 0.01$ & $14-\phi$ & asto) \\
\hline (high & $=02(14) . \mathrm{f}$ & eqA & 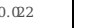 & 1.646 & $30.7\}$ & $0.0091 *$ & 45.97 & 10.846 & 0.7 & fo.(B) $1 *$ & 7.138 & & 3.646 & 0.7 & .120 \\
\hline Lymph & cyte3roburit & tian & 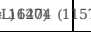 & $14807(1$ p & $00-10$ & 1730205 (1) & $143-111999)(114$ & $43-11 \mathbb{B E S}(120$ & $200-10$ & Henta488 (1 150 & $50-18823(1$ & 154 & -113347 (1200 & -11 & 8936 \\
\hline (low & 1000 ). fre & q. 4 & 1.733 & 2.453 & 35.30. & $26 \pi 3$ & 8.820 & 30.853 & 5.3 & 306 & 9.448 & & 6.153 & 5.38. & .588 \\
\hline $\mathrm{CRP}(\mathrm{m})$ & /Lif9.38 (4) & 1.5 & $3-7 \pi 59.90 \times) \times 5$. & 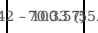 & $5.95-\phi$ & $80(162), 46$ & $0.04-8 \pi .6 \square \times 2$. & $2.24-7018.095$ & $5.90-d$ & 6. (822) 76 (22. & $21-\pi 6 . A B 2 x \phi$ & 8.5 & - -301.33$)(\$ 5$. & $96-\phi$ & 302927) \\
\hline (high & 54.1freq. & & 5.482 & 0.4123 & 2.o. & 4551 & $\$ 3.52$ & 0.0123 & 2.00 & 5715 & 8.2108 & & 1.2123 & 2.00 . & .739 \\
\hline Ferritit & 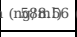 & 412 & $6539(842.230$ & 9. 98453180. & 377.735. & $=06502449 \mid 4$ & 400.187629 .0220 & 164.60153 .83 .73 & 37.75 & $-16 \operatorname{sis} 02483$ & 20.8269 .93$. & 2384 & 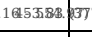 & 80.79 & (15\%0.41) \\
\hline (high & $=4 D D D$. fre & q. 4 & 3.835 & 4.356 & 37.35 & 26537 & 3.519 & 29.256 & 37.3 & .073 & 9.451 & & 3.36 & 7.3. & .473 \\
\hline Procalc & torfirs 8itgin & nills & - B..398)(d.25 & $5-2.6877)(d .4$ & $452-8$ & $85 \pi) 39$ (. & 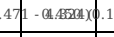 & $118-n .4867 x$ & $452-9$ & . & $068-10,172 x)$ & & - B.A010) & $52-4$ & (mina) \\
\hline (high & $=04500) . \mathrm{f}$ & reqs & 312 & 1.816 & $10 . \pi$ & 5280 & 1.8 & 9.216 & $0 . \pi$ & .618 & .016 & & 2.016 & .7. & 218 \\
\hline D-DIMA & $R(\lim 47001$. & $32-$ & 3.9219 (1. 63 & 5.2596 (1. 36 & $36-4.28$ & 355274 (1) 6 & \begin{tabular}{l|l|l}
22 & $4.3933 ~(1.62$ \\
\end{tabular} & $2-5.3596(1) 86$ & 4. & $3771.92(0.59$ & $1.302)^{2}(1)$ & 93. & 4.8986 (1. 86 & 4. & 3086 \\
\hline (high & $=0330) . \mathrm{fr}$ & q. 8 & 1.676 & 4.5107 & 11.3 & 2167 & 87.150 & 6.9107 & 1.3 & 186 & 2.98 & & 3.7107 & 1.38. & .090 \\
\hline
\end{tabular}

Table 8. Laboratory Correlations with Gender and Age Related HGST

\begin{tabular}{|c|c|c|c|c|c|c|c|c|c|c|c|c|c|}
\hline & \multicolumn{7}{|c|}{ Female } & \multicolumn{6}{|c|}{ Male } \\
\hline & \multicolumn{3}{|c|}{ Normal (n:30) } & \multicolumn{3}{|c|}{ Lower (n:43) } & & \multicolumn{3}{|c|}{ Normal (n:38) } & \multicolumn{3}{|c|}{ Lower (n:39) } \\
\hline & & $\begin{array}{l}\text { Confiden } \\
\text { Interval } \\
\text { (Bootstra }\end{array}$ & & & $\begin{array}{l}\text { Confide } \\
\text { Interval } \\
\text { (Bootstr }\end{array}$ & & & & $\begin{array}{l}\text { Confiden } \\
\text { Interval } \\
\text { (Bootstra }\end{array}$ & & & $\begin{array}{l}\text { Confiden } \\
\text { Interval } \\
\text { (Bootstra }\end{array}$ & \\
\hline $\begin{array}{l}\text { Lab } \\
\text { Findings }\end{array}$ & Mean & Min & $\operatorname{Max}$ & Mean & Min & Max & Sign & Mean & Min & Max & Mean & Min & $\operatorname{Max}$ \\
\hline $\mathrm{LDH}$ & 288.97 & 252.57 & 326.8 & 361.49 & 318.53 & 408.34 & $0.027 *$ & 332.18 & 290.04 & 386.15 & 335.26 & 273.24 & $\overline{409 .:}$ \\
\hline CK & 192.20 & 108.10 & 344.84 & 109.19 & 78.91 & 145.17 & 0.419 & 202.03 & 141.90 & 275.90 & 220.90 & 155.06 & $301 . !$ \\
\hline Troponin T & 0.007 & 0.005 & 0.010 & 0.040 & 0.012 & 0.090 & 0.388 & 0.012 & 0.008 & 0.018 & 0.032 & 0.017 & $\overline{0.05:}$ \\
\hline Lymphocyte & 1640.00 & 1381.72 & 1884.82 & 1097.67 & 939.91 & 1291.03 & $0.003^{*}$ & 1281.58 & 1059.47 & 1575.11 & 1305.13 & 1100.17 & 1512 \\
\hline CRP & 36.00 & 17.07 & 63.15 & 74.08 & 52.39 & 96.18 & $0.020 *$ & 97.44 & 58.44 & 148.13 & 66.18 & 43.93 & $\overline{94.3 !}$ \\
\hline Ferritin & 184.97 & 101.19 & 303.72 & 399.49 & 258.39 & 571.07 & $0.042 *$ & 574.54 & 425.53 & 758.27 & 602.93 & 431.57 & 811.6 \\
\hline Procalcitonin & 0.212 & 0.066 & 0.459 & 2.536 & 0.201 & 5.925 & 0.215 & 0.124 & 0.088 & 0.165 & 2.333 & 0.192 & 5.15\{ \\
\hline D-Dimer & 3.81 & 0.99 & 8.72 & 2.65 & 1.76 & 3.62 & 0.628 & 1.66 & 0.78 & 3.18 & 3.89 & 1.46 & 7.45 \\
\hline
\end{tabular}

